\title{
Laparoscopic Ureteric Reimplantation in Distal Ureteric Injury Post-total Laparoscopic Hysterectomy: A Case Series
}

\author{
Chandra P Dadhich ${ }^{1}$, Nidhi Mehta ${ }^{2}$, Tripti Dadhich ${ }^{3}$, Anita K Sharma ${ }^{4}$, Disha Gupta ${ }^{5}$, Priyanka Asodariya ${ }^{6}$
}

\begin{abstract}
Introduction: Ureteral injuries have been recognized as a potential complication of gynecological surgical procedures since the inception of our discipline; incidence ranging from 0.5 to $1.5 \%$ and morbidity associated with it may be serious. Traditionally, most ureterovaginal fistulas have been repaired by ureteroneocystostomy. Open ureteral reimplantation is a potentially morbid surgical procedure. Endourological techniques are highly successful in treating posthysterectomy ureteral injuries. The objective of this presentation is to relate our experience and result with laparoscopic ureteral reimplantation.

Materials and methods: Five patients with complaints of leakage of urine per vaginum postoperatively on day 12-24 (post-TLH) presented for treatment. After diagnosis, treatment of ureterovaginal fistula was performed completely laparoscopically. Laparoscopic ureteral reimplantation was done.

Results: No major intraoperative or postoperative complications were encountered. The operating room time was 120 minutes (range 120-240 minutes). The average hospital stay was 4 days. Patients had a successful outcome defined as no evidence of radiographic obstruction and no clinical complaints of persistent renal colic or any other urinary symptoms.

Conclusion: Our experience demonstrates that laparoscopic ureteral reimplantation is an effective minimally invasive treatment option for distal ureteral strictures.

Keywords: Distal ureteral strictures, Ureteric reimplantation, Ureterovaginal fistula.

Journal of South Asian Federation of Obstetrics and Gynaecology (2020): 10.5005/jp-journals-10006-1826
\end{abstract}

\section{INTRODUCTION}

The total incidence of ureteral injury after gynecological surgery is reported to be $0.5-1.5 \%$. Currently, the reported rate of ureteral injury varies between $0.5 \%$ (experienced surgeons) and $14 \%$ (inexperienced surgeons) after laparoscopic hysterectomy. ${ }^{1}$ Risk factors for the development of ureterovaginal fistulae include endometriosis, obesity, pelvic inflammatory disease, as well as radiation therapy and pelvic malignancy. The morbidity associated with such injury may be serious, resulting in increased hospital stay, compromise of the original surgical outcome, secondary invasive interventions, reoperation, potential loss of renal function, and deterioration of the patient's quality of life. Hence, thorough knowledge of ureteric and pelvic anatomy and prompt laparoscopic intervention of ureterovaginal fistula (laparoscopic ureteric reimplantation) discovered post-laparoscopic hysterectomy is safe and effective, with prompt resolution of urinary leakage, rapid postoperative recovery, and a high degree of patient satisfaction.

\section{Aim and Objective}

The objective of this presentation is to relate our experience and result with laparoscopic ureteral reimplantation in postoperative cases of total laparoscopic hysterectomy.

\section{Materials and Methods}

Patients operated for total laparoscopic hysterectomy in v/o recurrent and chronic pelvic pain with grade IV endometriosis and frozen pelvis; presented to our gynecology OPD on their postoperative day 12-24 with complaints of leakage of urine per vaginum and urinary incontinence. Ultrasound and CT scan performed showed unilateral ureterovaginal fistula (Fig. 1). $\overline{{ }^{1-6} \text { Department of Obstetrics and Gynaecology, Eternal Heart Care }}$ Centre, Eternal Heart Hospital, Jaipur, India

Corresponding Author: Nidhi Mehta, Department of Obstetrics and Gynaecology, Eternal Heart Care Centre, Eternal Heart Hospital, Jaipur, India, Phone: +91 9829092596, e-mail: drnidhimehta83@rediffmail. com

How to cite this article: Dadhich $\mathrm{CP}$, Mehta N, Dadhich $\mathrm{T}$, et al. Laparoscopic Ureteric Reimplantation in Distal Ureteric Injury Posttotal Laparoscopic Hysterectomy: A Case Series. J South Asian Feder Obst Gynae 2020;12(5):291-294.

Source of support: Nil

Conflict of interest: None

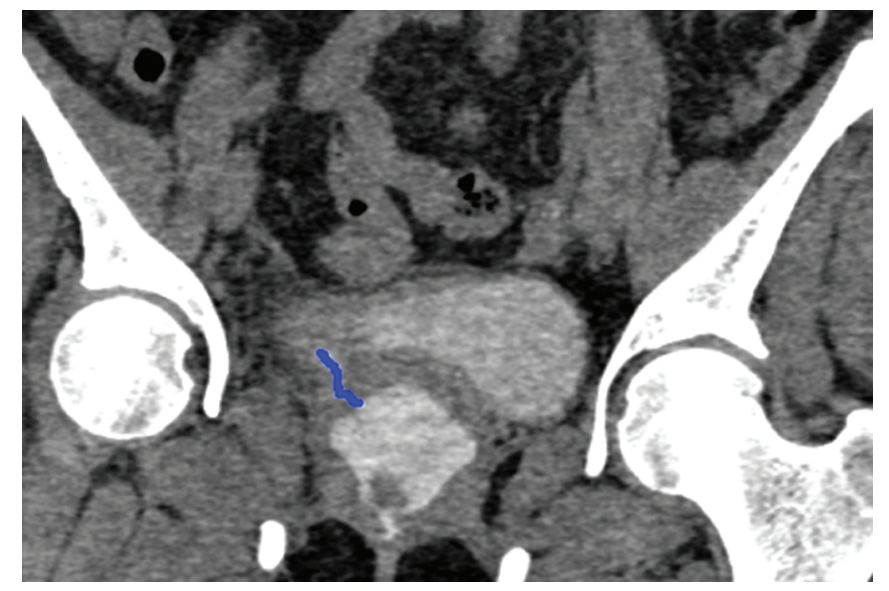

Fig. 1: MRI picture of ureterovaginal fistula

(c) Jaypee Brothers Medical Publishers. 2020 Open Access This article is distributed under the terms of the Creative Commons Attribution 4.0 International License (https://creativecommons.org/licenses/by-nc/4.0/), which permits unrestricted use, distribution, and non-commercial reproduction in any medium, provided you give appropriate credit to the original author(s) and the source, provide a link to the Creative Commons license, and indicate if changes were made. The Creative Commons Public Domain Dedication waiver (http://creativecommons.org/publicdomain/zero/1.0/) applies to the data made available in this article, unless otherwise stated. 
D-J stenting was done but as there was no relief and symptoms persisted even after 8 weeks; the decision for laparoscopic ureteric reimplantation was taken. Informed consent was taken. After a full preoperative workup and pre-anesthetic checkup; a 4-port video laparoscopy was done. On laparoscopy, dense omental adhesions were released and left pelvic wall structures were identified. The left side retroperitoneum was opened and the ureter dissected free up to its entry into the bladder. The lower end of the ureter was released from the vagina and freshened to remove the fibrous tissue. The bladder was filled with saline through the Foley catheter in the urethra and the catheter clamped. Site of fistula identified. Dissection in space of Retzius was done due to shortening of ureter so that ureterovaginal anastomosis be made tension free. Cystoscopic sheath passed into the bladder through the urethra and cystotomy done. D-J stent was passed from the bladder into the abdominal cavity; stay sutures applied posteriorly. The stent was passed into the lower cut end of the ureter and fixed via five interrupted sutures placed circumferentially. The stent was then reinforced into bladder musculature and ureteroneocystostomy was done. Further, the lateral bladder wall was fixed to the psoas muscle by two interrupted sutures, thereby performing a psoas hitch. Cystoscopy was done to check the anastomosis and position of the D-J stent.

The patency and integrity of the anastomosis was checked via diagnostic laparoscopy. Hemostasis was ensured and an abdominal drain was put which was removed on postoperative day 3. Ports were closed and patients were put on i.v. antibiotics for 3 days and oral for 10 days. The self-retaining catheter was put for 14 days. Patients were discharged on post-op day 4 and follow-up was done. D-J stent was removed after 6 weeks and to our delight patient had a successful outcome defined as no evidence of radiographic obstruction and no clinical complaints of persistent renal colic or any other urinary symptoms (Figs 2 to 10).

\section{Discussion}

The introduction of laparoscopy to gynecological surgery has allowed for both innovative advancements and new challenges in the field. Ureteral complications with gynecological surgery may be quite morbid; therefore, knowledge about their prevention, diagnosis, and management is of the utmost importance. We estimate the incidence of ureteral injury (including transection, obstruction, fistula formation, and necrosis from thermal injury) during gynecological laparoscopy as ranging from $<1$ to $2 \%$. $^{2}$ The injury occurs most frequently in the lower third of the ureter (51\%), followed by the upper third (30\%) and the middle third (19\%). ${ }^{3}$

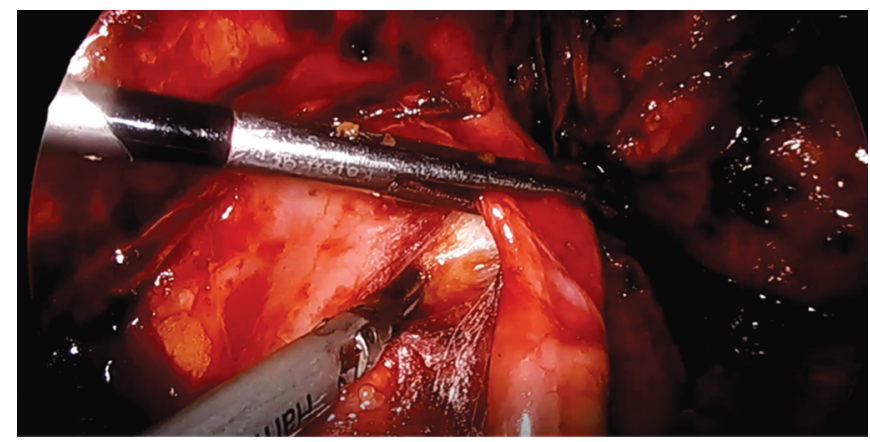

Fig. 2: Identification of ureter at ureteric tunnel
The most common sites of injury are:

- Lateral to the uterine vessels.

- The area of the ureterovesical junction close.

- To the cardinal ligaments.

- The base of the infundibulopelvic ligament.

- As the ureters cross the pelvic brim at the.

- Ovarian fossa.

- At the level of the uterosacral ligament.

During laparoscopy, the ureter is injured most frequently adjacent to the uterosacral ligaments and most commonly due to thermal injury caused by lateral spread especially while using bipolar cautery in cases with dense adhesions.

Preoperative evaluation is useful in identifying patients who are at higher risk of ureteral injury. Patients undergoing gynecological surgery for malignancy may have a higher baseline risk of ureteral injury-as high as $5-8 \%$. Other potential risk factors include sources of anatomic distortion such as previous pelvic surgery, endometriosis, pelvic adhesions, enlarged uteri, adnexal masses, cervical and broad ligament fibroids, as well as congenital anomalies. It has also been suggested that intraoperative hemorrhage is associated with ureteral injury when the visualization of the operative field is obscured. In cases where there is a high clinical index of suspicion of ureteral anatomic distortion, preoperative imaging of the genitourinary tract is recommended. Some experts have also suggested the prophylactic placement of ureteral stents in select cases to aid in intraoperative ureteral identification. Intraoperative measures to prevent injury include an appropriate operative approach, adequate exposure, full examination of the disease in the pelvis. Avoiding blind clamping of blood vessels; and adequate mobilization of the bladder. Caution is necessary while using laser and electrocautery because a large proportion of ureteric injuries during laparoscopic surgery are associated with diathermy. Short applications are likely to reduce the risk of ureteric injury. Surgical management of ureteric injuries depends on the site and size of the defect; type of injury and condition of the patient and expertise of the surgeon. ${ }^{4}$

\section{Results}

No major intraoperative or postoperative complications were encountered. The operating room time was 120 minutes (range 120-240). The average hospital stay was 4 days. Patients had a successful outcome defined as no evidence of radiographic obstruction and no clinical complaints of persistent renal colic or any other urinary symptoms (Table 1).

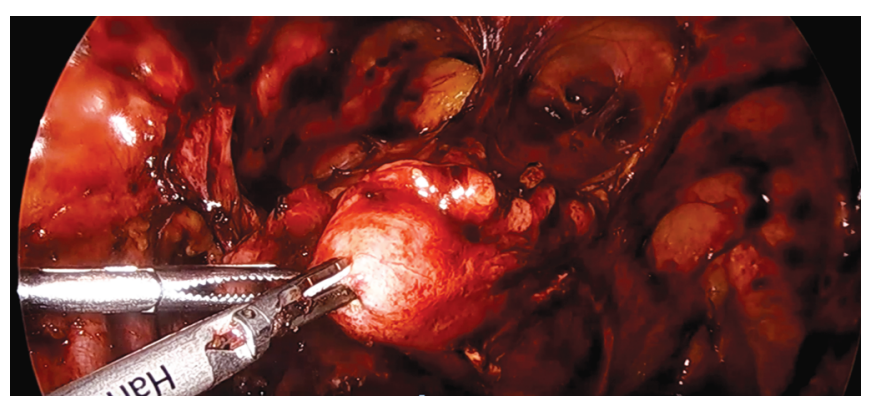

Fig. 3: Cystostomy incision 

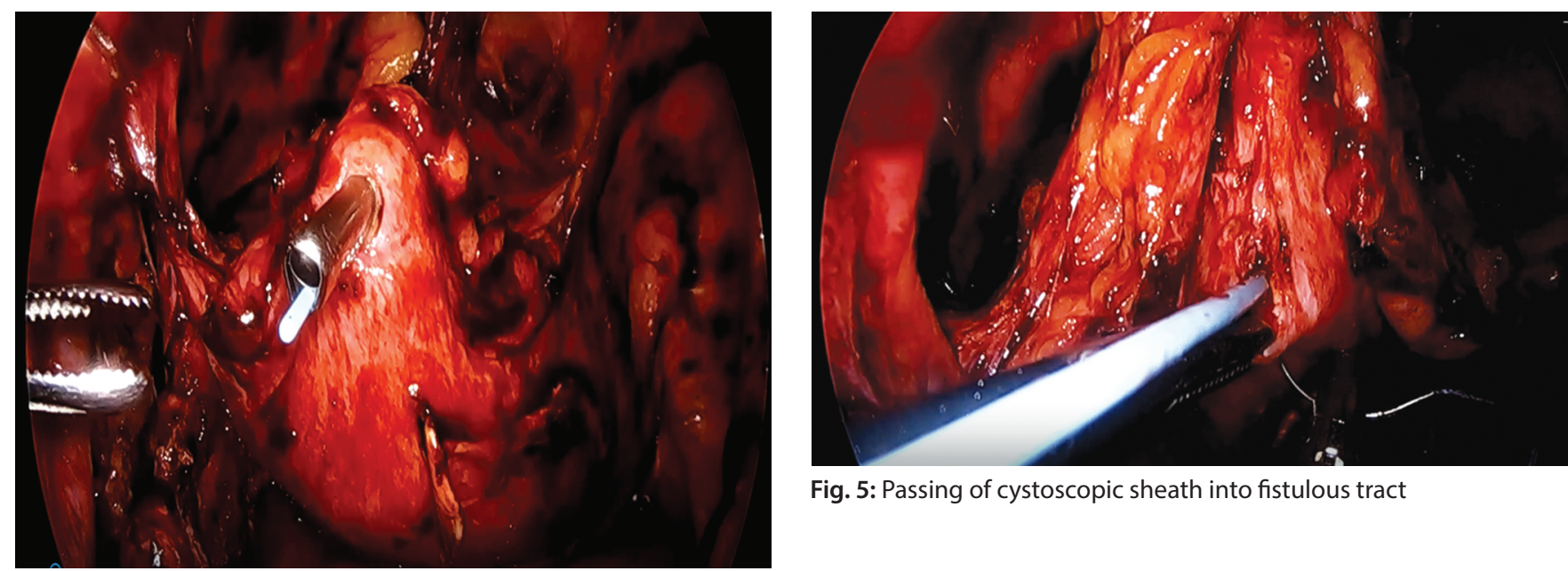

Fig. 5: Passing of cystoscopic sheath into fistulous tract

Fig. 4: Passing of guidewire through cystoscopic sheath

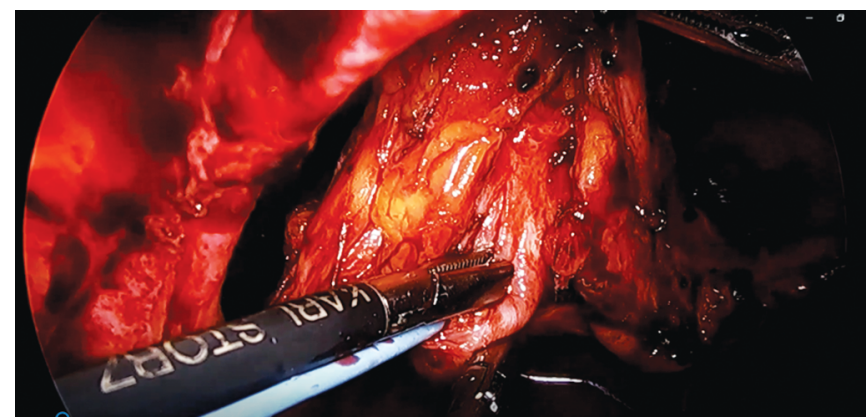

Fig. 6: Passing of guidewire into cystoscopic sheath

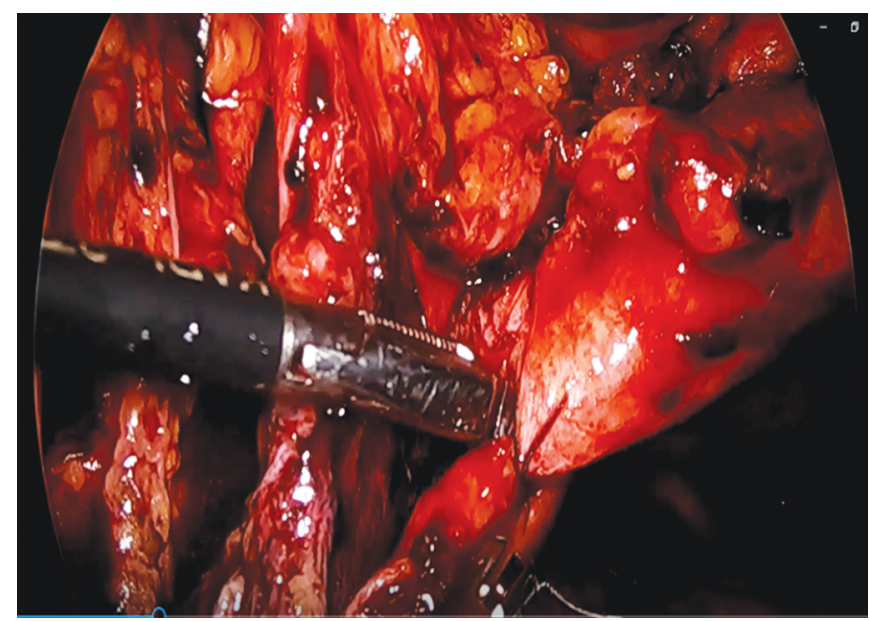

Fig. 8: Suturing of stent over reanastomosis

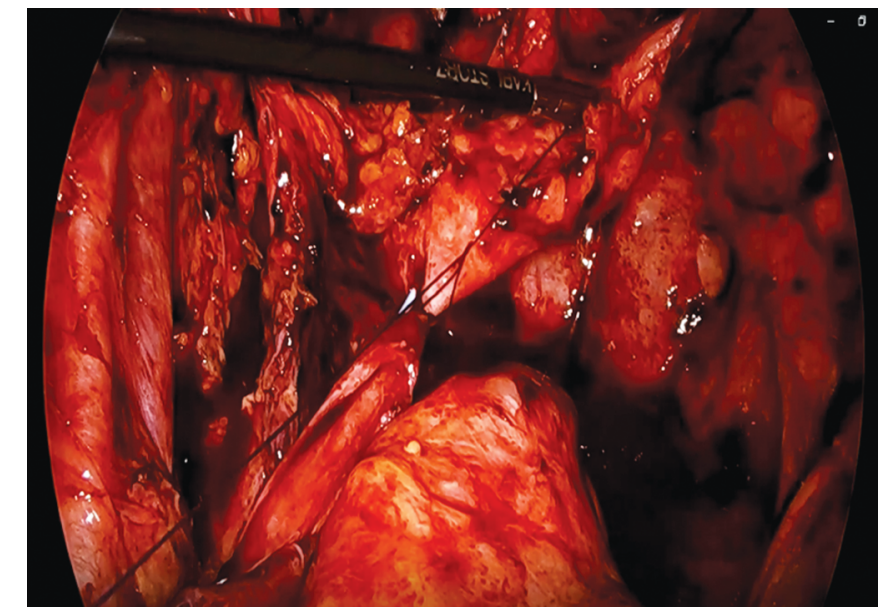

Fig. 7: Neocystostomy

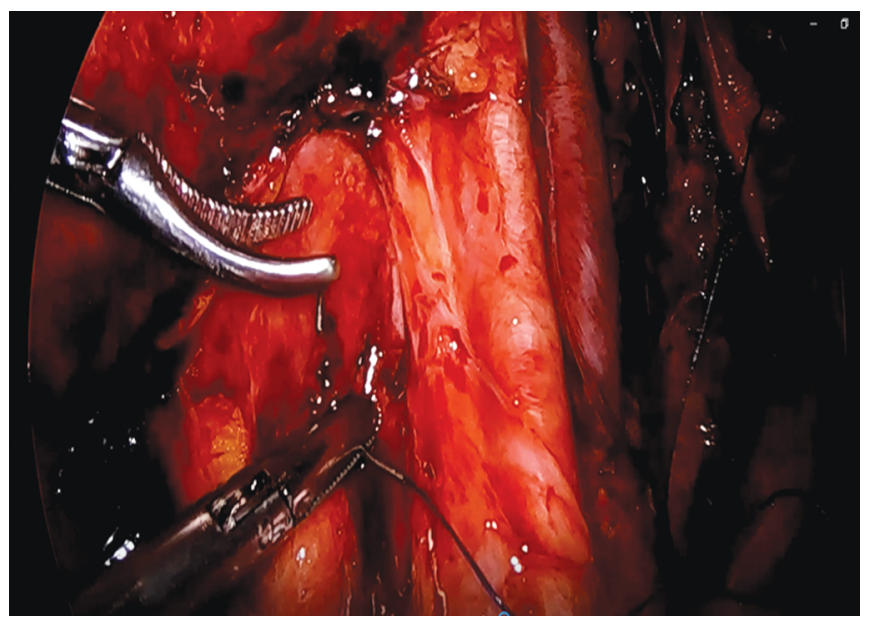

Fig. 9: Reanastomosis

intervention of ureterovaginal fistula discovered post-laparoscopic hysterectomy is safe and effective, with prompt resolution of urinary leakage, rapid postoperative recovery, and a high degree of patient satisfaction. 


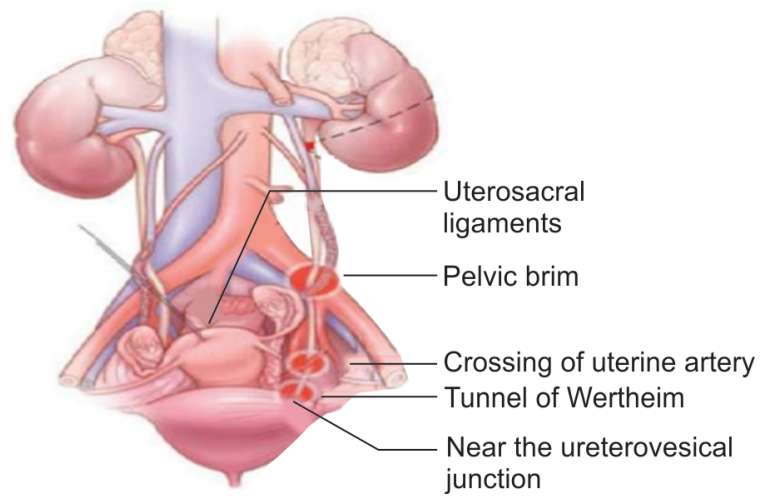

Fig. 10: Common sites of ureteric injury during gynecological surgeries

\section{References}

1. Manoucheri $\mathrm{E}$, Cohen SL, Sandberg EM, et al. Ureteral injury in laparoscopic gynecologic surgery. Rev Obstet Gynecol 2012;5(2): 106-111.
Table 1: Repair options for ureteric injuries according to its location

\begin{tabular}{lll}
\hline $\begin{array}{l}\text { Location of } \\
\text { injury }\end{array}$ & Best repair options & Secondary repair options \\
\hline Upper third & $\begin{array}{l}\text { Uretero- } \\
\text { ureterostomy }\end{array}$ & $\begin{array}{l}\text { Transuretero-ureterostomy } \\
\text { ureterocalycostomy }\end{array}$ \\
Middle third & $\begin{array}{l}\text { Uretero- } \\
\text { ureterostomy }\end{array}$ & $\begin{array}{l}\text { Transuretero-ureterostomy } \\
\text { boari flap }\end{array}$ \\
Lower third & Direct reimplantation & Psoas hitch \\
Complete & lleal interposition & Nephrectomy (last resort \\
ureteral loss & autotransplantation & only) \\
\hline
\end{tabular}

Permission obtained from Elsevier Ltd $\odot$ Armenakas, N. Atlas Urol. Clin. North Am. 6, 71-84 (1998)

2. Gild $P$, Kluth $L A$, Vetterlein $M W$, et al. Adult iatrogenic ureteral injury and stricture-incidence and treatment strategies. Asian J Urol 2018;5(2):101-106.

3. Divya PV, Ranade RR, Kulkarni P, et al. Urological reconstructions in gynecological oncology. Indian J Gynecol Oncolog 2019;17:1.

4. Nerli RB, Ghagane SC, Kadeli V, et al. Ureteric injuries during laparoscopic gynecologic surgeries. J Sci Soc 2019;46:3-7. 